\title{
Evaluation of a gluten-free sourdough bakery product
}

\author{
ANIKÓ KOVÁCS* ㅁ, RAUL KOLINKA, GYÖRGYNÉ KÓCZÁN and \\ ZOLTÁN KÓKAI
}

Hungarian University of Agriculture and Life Sciences, Villányi Street 29-43, 1118 Budapest, Hungary

\section{CONFERENCE FULL PAPER}

Received: June 1, 2021 • Accepted: July 30, 2021

Published online: August 25, 2021

(c) 2021 The Author(s)

\begin{abstract}
The population of gluten sensitive people has been gradually rising in the last decades. The food industry, especially the bakery industry has to develop more gluten-free products to satisfy the consumer's demand. However, the quality of these products differs from the quality attributes of a standard glutenious bakery product. Therefore, the aim of our research was to develop a good quality gluten-free sourdough product with 3 different gluten-free flours: millet, brown rice and a commercially available mixture (Belbake). We investigated the differences in moisture content, the baking loss, the texture and the sensory properties of the products. According to our results in the case of the moisture content the brown rice sample had the highest, while the millet gave the lowest value. The baking loss measurement gave reverse results. In the texture analysis the brown rice sample was the softest, but the millet and the Belbake had better results in resilience and in springiness. Also, in the sensory analyses the Belbake product was found to be the best by the judges, however, there were no significant differences between them. In conclusion, the product development of a gluten-free sourdough bakery product was successful. Further research is needed to investigate the shelf life of the products.
\end{abstract}

\section{KEYWORDS}

gluten-free, sourdough, millet, brown rice

\footnotetext{
*Corresponding author. E-mail: Kovacs.Aniko94@uni-mate.hu
} 


\section{INTRODUCTION}

The food industry, like lots of other industry, is constantly changing, due to the newer trends, food intolerances and different illnesses, which occur in the world. These changes sometimes mean big challenges, however, they also provide opportunities to develop new, diversified and healthier foods. In the 21th century the consumer's lifestyle and eating habits have been changing and to the new demands all food companies - including the bakeries - have to adapt (Marudova et al., 2020).

International studies proved that the gluten sensitivity is one of the most common lifelong disorders, which concern $1 \%$ of the European population (Mustalahti et al., 2010). According to Singh et al. (2018) this number is even higher nowadays. They found that the presence of the sensitivity in global is $1.4 \%$ based on serological tests and $0.7 \%$ based on biopsy.

Many people self-diagnose themselves with gluten sensitivity, which is most of the time not confirmed by a specialist, but we could surely state that nowadays the number of gluten sensitive people is increasing, also, according to the forecast, this number will be rising further in the future. Zorzi et al. (2020) wrote in their research that predictably between 2020 and 2027 the demand for gluten-free products will be increased by $9.2 \%$, in which the gluten-free bakery products will be in the highest ratio. On the other hand, the gluten-free diet is getting more and more popular and lots of people start to follow these eating habits without having the food intolerance. Also, in small households it is often observed that if one person is affected in the food intolerance, the other members of the family also switch to this diet, to make the meals and shopping easier. Due to the abovementioned reasons, the bakery industry must use new ingredients, technologies or methods to make more and better quality products for the gluten sensitive consumers (Biró et al., 2019). One method for producing gluten-free products is well known and has existed since ancient times: the making of sourdough. This method has some advantageous effects, like flavour, aroma, texture development and better digestion of the products due to the fermentation. More research proved that this method could be effective for making gluten-free breads and other bakery products (Różyło et al., 2016; Moroni et al., 2009; Di Cagno et al.; 2010; Picozzi et al., 2016).

In the industry wheat or rye are often used to make sourdough, however, these grains are not gluten-free, therefore other grains or pseudocereals need to be used to produce these kinds of products. Making sourdough or even dough by using gluten-free grains is not easy, due to the missing gluten-forming proteins in the flours, however, the challenge is feasible. Unfortunately, there is only little research about this topic (Różyło et al., 2016; Moroni et al., 2009; Di Cagno et al.; 2010; Picozzi et al., 2016).

Two well-known grains could be used for developing a gluten-free bakery product, one is millet, the other one is brown rice. Millet is an ingredient that has a pleasant taste, an alkaline effect, it is rich in fibre, a good source of plant protein and it has an outstanding nutritional value (Léder F, 2013). The other grain is rice, which is now grown everywhere around the world (Rosell and Marco, 2008). Rice is one of the best-known gluten-free grains in addition to maize and it is one of the most important ingredients in the gluten-free kitchen. It has a lower protein content than wheat, however, among the proteins of cereal grains it has the most beneficial amino acid composition. Brown rice flour is digested slower than white wheat flour and white rice flour, which means that it has a lower glycemic index, therefore it is recommended for diabetics (Internet 2). 
The aim of our study was to find out which one of the abovementioned flours (brown rice flour or millet) is the most suitable for the development of a gluten-free sourdough bakery product. The goal was to achieve a good quality product, which could be an alternative to the commercial gluten-free products.

\section{MATERIALS AND METHODS}

In our research, we used 3 different kinds of flour: millet, brown rice and a commercially available gluten-free flour mixture (Belbake: mixture of rice flour and starch, the ratio is not declared by the manufacturer). The Belbake was chosen to evaluate the behaviour of the commercial flour mixture compared to plain flours. Our products contained $350 \mathrm{~g}$ flour, $85 \mathrm{~g}$ sourdough, $4 \mathrm{~g}$ sugar, $8 \mathrm{~g}$ salt, $5 \mathrm{~g}$ yeast, $75 \mathrm{~g}$ sour cream, half egg, $30 \mathrm{~g}$ olive oil and $100 \mathrm{ml}$ water. All the ingredients were commercially available. The only difference between the products were the type of the flour used.

For making our products first we needed to make the sourdough, which was spontaneously fermented at $25-27^{\circ} \mathrm{C}$ and only made from flour and water (1:1 ratio). Every day we took out $50 \mathrm{~g}$ of the sourdough and we fed it with $50 \mathrm{~g}$ flour and around $50 \mathrm{ml}$ water. It was fed for 4 days. On the $5^{\text {th }}$ day we mixed it with the other ingredients. After the dough was ready and all the ingredients were completely mixed with each other, we divided it to achieve around $115 \mathrm{~g}$ products, we got 6 pieces of sample from a dough, The dough was leavened for $40 \mathrm{~min}$ in a controlled environment (at $32{ }^{\circ} \mathrm{C}$ and $80 \%$ of relative humidity). Then the samples were baked for $16 \mathrm{~min}$ at $180^{\circ} \mathrm{C}$. After cooling in room temperature $\left(\sim 22^{\circ} \mathrm{C}\right)$ for half an hour the moisture content, baking loss, texture and sensory properties were measured.

\section{Moisture content, baking loss}

Moisture content was measured with Sartorius MA 50 automatic moisture content measuring device. We put $2.5 \mathrm{~g}$ sample into the device, which was than drying the samples at $105^{\circ} \mathrm{C}$ till achieving the weight equilibrium. All samples were measured 3 times.

For calculating the baking loss we measured the weight of the formed dough before baking and after baking when it was cooled down. Than we used the following equation:

$$
\text { Bake loss }(\%)=\left(\frac{\text { Dough weight }}{\text { Baked product weight }}-1\right) * 100
$$

\section{Texture analyses}

The texture of the three different samples was analysed with Stable Micro System TA-XT2i universal texture measurement device. We applied the Texture Profile Analyses (TPA) method to investigate the bakery products. A $20 \mathrm{~mm}$ diameter plate as probe was used. The method imitates the human chewing with 2 compression circles. The initial speed of the measuring probe was $1 \mathrm{~mm} / \mathrm{s}$, the text speed was $5 \mathrm{~mm} / \mathrm{s}$. The compression was $40 \%$ of the original heights. The measurements were done 5 times, each sample was $25 \mathrm{~mm}$ high. From the measured curves the software calculated the hardness, adhesiveness (negative work between the two cycles), cohesion (Area 2/Area 1), springiness (Distance 2/Distance 1), gumminess (Hardness* Cohesiveness), chewiness (Hardness*Cohesiveness*Springiness) and resilience (Area 4/Area 3) (Fig. 1). 


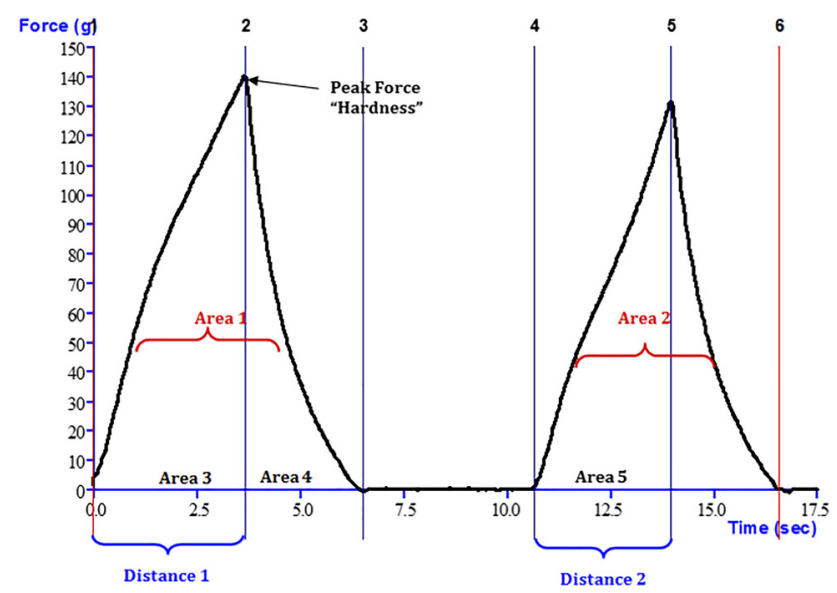

Fig. 1. TPA curve (Internet 1)

\section{Sensory analyses}

Sensory analyses were done by 37 untrained people, among them one was gluten sensitive and 3 were lactose sensitive. Most of the judges had already tasted gluten-free and sourdough products. They had to judge the products in 7 different attributes on a 1-5 scale, where 1 was the worst and 5 was the best. The attributes were: odour, colour, crust, crumb, taste, after taste and general impression.

\section{Statistics}

The results were statistically analysed with one-way ANOVA $(P=0.05)$. If there were significant differences Games-Howell and Tukey post-hoc tests were carried out.

\section{RESULTS AND DISCUSSION}

\section{Moisture content}

The average water content of the samples was between 35 and $38 \%$.

Our results (Fig. 2) show that the brown rice sample had the highest while millet had the lowest water content. According to the ANOVA there were significant differences between the samples. The post-hoc test showed that the brown rice and the millet sample's water content value was different.

\section{Baking loss}

Table 1 summarises the results of the baking loss calculation, the average loss was between 7.2 and $8.2 \%$.

The millet sample had the highest value and the brown rice sample had the lowest value, which is in an inverse relationship with the water content results. In the industry these values would not be considered as an outstanding baking loss. 


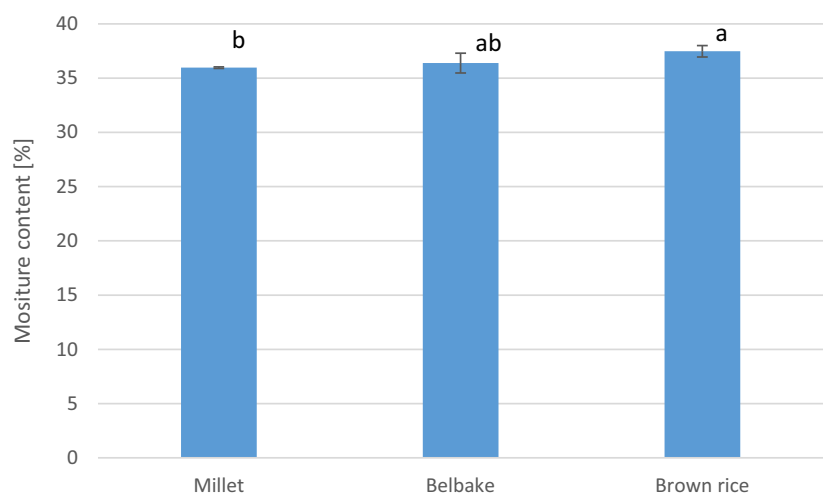

Fig. 2. Average mositure content results. Different letters indicate significant differences $(P=0.05)$

Table 1. Baking loss results

\begin{tabular}{lcccccc}
\hline & & \multicolumn{4}{c}{ Final weight $(\mathrm{g})$} & \\
\cline { 3 - 5 } Samples & Initial weight $(\mathrm{g})$ & 1 & 2 & 3 & Average (g) & Baking loss (\%) \\
\cline { 3 - 5 } Millet & 115 & 106.51 & 106.37 & 106.05 & 106.31 & $\mathbf{8 . 1 7}$ \\
Belbake & 115 & 106.81 & 107.62 & 106.32 & 106.92 & $\mathbf{7 . 5 6}$ \\
Brown rice & 115 & 107.08 & 106.90 & 107.57 & 107.18 & $\mathbf{7 . 2 9}$ \\
\hline
\end{tabular}

\section{Texture analyses}

Figure 3 shows the average TPA curves of the different samples. From the curves we could see that in the first compression cycle the millet sample gave the highest force value, however, in the second cycle it was the Belbake. In the case of the millet product the difference between the second and the first force was bigger than in the case of the Belbake product, which here indicated that the crumb was easier to chew. Among the 3 different bakeries the brown rice one results were the best, these samples had the softest crumb and the loosest structure.

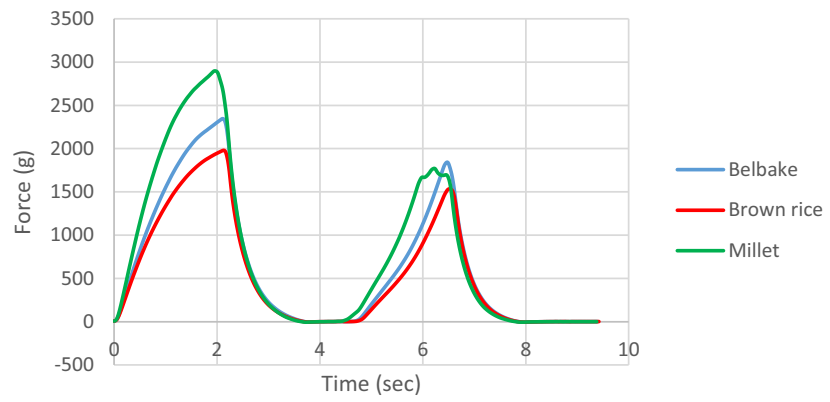

Fig. 3. Measured average TPA curves $(n=5)$ 
From the curves the software calculated different texture properties which are shown in Table 2.

According to our results, the millet sample had the highest while the brown rice sample had the lowest values in the case of hardness, gumminess and chewiness. The adhesiveness and the gumminess are highly correlated attributes, it specifies how much the dough sticks to the measuring probe after compression. The chewiness of the sample indicates that from the 3 samples the brown rice one is easier to chew and to consume, which we could also see in Fig. 3. In cohesion and in resilience the Belbake sample had the highest value, this means that this bakery product regains its original height or shape better. However, in springiness, the millet sample was the best. We could see that the products which had higher chewiness value were better in springiness. The statistical analyses (ANOVA) showed that there were significant differences in hardness, gumminess, and chewiness. In these parameters each sample gave significant differences (post-hoc), only in chewiness between the Belbake and brown rice was there no difference.

Table 2. Calculated average values from the TPA measurement. Different letters indicate significant differences $(P=0.05)$

\begin{tabular}{lccc}
\hline & Belbake & Brown rice & Millet \\
\hline Hardness (N) & $23.08 \pm 1.667^{\mathrm{b}}$ & $19.48 \pm 1.67^{\mathrm{c}}$ & $29.01 \pm 0.92^{\mathrm{a}}$ \\
Adhesiveness (gs) & $-1.044 \pm 0.55$ & $-0.741 \pm 0.301$ & $-1.436 \pm 0.41$ \\
Cohesion (-) & $0.51 \pm 0.013$ & $0.498 \pm 0.017$ & $0.49 \pm 0.025$ \\
Springiness (\%) & $94.61 \pm 7.64$ & $92.313 \pm 1.49$ & $97.33 \pm 5.72$ \\
Gumminess (N) & $11.78 \pm 0.95^{\mathrm{b}}$ & $9.71 \pm 0.995^{\mathrm{c}}$ & $14.17 \pm 1.04^{\mathrm{a}}$ \\
Chewiness (N) & $11.16 \pm 1.46^{\mathrm{b}}$ & $8.96 \pm 0.85^{\mathrm{b}}$ & $13.82 \pm 1.67^{\mathrm{a}}$ \\
Resilience (\%) & $26.75 \pm 1.79$ & $25.45 \pm 1.30$ & $24.63 \pm 1.75$ \\
\hline
\end{tabular}

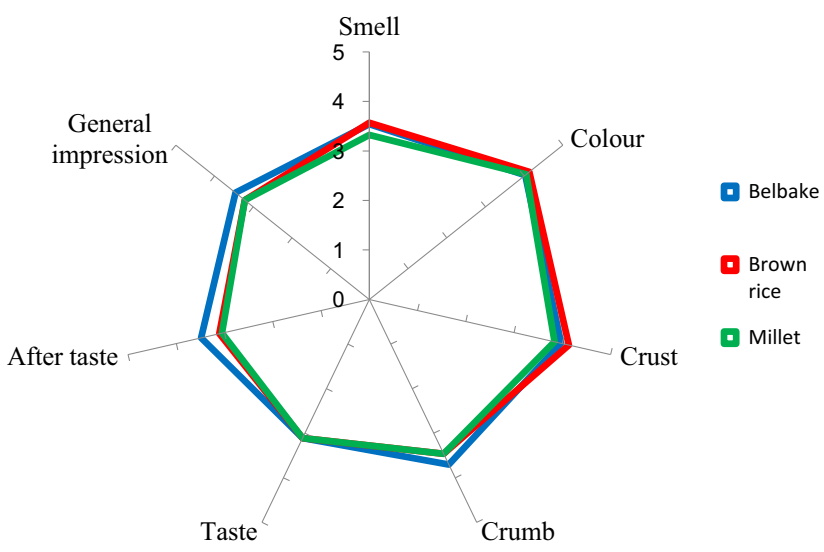

Fig. 4. Sensory analyses result 


\section{Sensory analyses}

All the products resulted in good sensory values in all attributes (Fig. 4), the judges found the Belbake sourdough product to be the best according to the general impression. However, there were no significant differences between the products in either attributes.

Based on the used ingredients we calculated the price for each sample. According to that there were also no big differences between the products, the millet rolls would be a little bit more expensive than the others. However, the calculated prices were cheaper than other gluten-free bakery products in the market. This provides a free choice for the bakery industry as to which products are worth producing from a technological and economical point of view.

\section{CONCLUSION}

The possibilities of a gluten-free sourdough bakery product development were examined. We used brown rice flour, millet flour, and a commercially available flour mixture (Belbake). We investigated the differences in moisture content, the baking loss, the texture and the sensory properties of the products. In the case of moisture content after baking the brown rice sample had the highest and the millet had the lowest value. The baking loss showed a reverse result (millet had the highest and brown rice had the lowest value), due to the inverse relationship between the two parameters. According to the TPA results, the brown rice sample in all texture attributes gave the smallest values. In the hardness it is beneficial, because it means that this sample had the softest texture, which could be due to the higher water content of the sample. However, in resilience and in springiness it is disadvantageous, because it means that it has a worse shape retention capability than the other samples. In these attributes the Belbake and the millet products were better. The sensory results also showed that the judges found the Belbake sample to be the best, but there were no big differences among the samples.

In conclusion our product development was successful. Our results indicate that there were no huge differences between the products in all attributes and this provides a free choice to the bakery industry as to whose production is worthy from a technological or economical point of view. Further research is needed to investigate the shelf-life of the products.

\section{REFERENCES}

Biró, B., Fodor, R., Szedljak, I., Pásztor-Huszár, K., and Gere, A. (2019). Buckwheat-pasta enriched with silkworm powder: technological analysis and sensory evaluation. LWT - Food Science and Technology, 116(2019): 108542.

Di Cagno, R., Barbato, M., Di Camillo, C., Rizello, C. G., De Angelis, M., Giuliani, G., De Vincenzi, M., Gobbetti, M., and Gobetti, M. (2010). Gluten-free sourdough wheat baked goods appear safe for young celiac patients: a pilot study. Journal of Pediatric Gastroenterology and Nutrition, 51: 777-783. https:// doi.org/10.1097/MPG.0b013e3181f22ba4.

Internet 1. Overview of texture profile Analysis chapter 4. What does TPA measure? https:// texturetechnologies.com/resources/texture-profile-analysis. 
Internet 2: Nemzeti Agrárgazdasági kamara Élelmiszeripari kézikönyv 2. Gluténmentes élelmiszerek (2018). https://www.nak.hu/kiadvanyok/kiadvanyok/2613-glutenmentes-elelmiszerek/file.

Léder, F. (2013). A köles „reneszánsza”. A köles hagyományos és új élelmiszeripari technológiái, elöadásjegyzet. Budapest.

Marudova, M., Stankov, S., and Baeva, M. (2020). Staling of sponge cakes with added emulsifiers. Progress in Agricultural Engineering Sciences, 16(S2): 101-108. https://doi.org/10.1556/446.2020.20012.

Moroni, A.V., Bello, F.D., and Arendt, E.K. (2009). Sourdough in gluten-free bread-making: an ancient technology to solve a novel issue? Food Microbiology, 26: 676-684. https://doi.org/10.1016/j.fm.2009.07. 001.

Mustalahti, K., Catassi, C., Reunanen, A., Fabiani, E., Heier, M., McMillan, S., Murray, L., Metzger, M. H., Gasparin, M., Bravi, E., Mäki, M., and Coeliac EU Cluster, Project Epidemiology (2010). The prevalence of celiac disease in Europe: results of a centralized, international mass screening project. Annals of Medicine, 42(8): 587-595. https://doi.org/10.3109/07853890.2010.505931.

Picozzi, C., Mariotti, M., Cappa, C., Tedesco, B., Vigentini, I., Foschino, R., and Lucisano, M. (2016). Development of a Type I gluten-free sourdough. Letters in Applied Microbiology, 62. https://doi.org/10. 1111/lam.12525.

Rosell, C. M., and Marco, C. (2008). Gluten-free cereal products and beverages. 4-Rice. Food Science and Technology, 81-100. https://doi.org/10.1016/B978-012373739-7.50006-X.

Różyło, R., Rudy, S., Krzykowski, A., and Dziki, D. (2016). Gluten-free bread prepared with fresh and freeze-dried rice sourdough-texture and sensory evaluation. Journal of Texture Studies, 47. https://doi. org/10.1111/jtxs.12180.

Singh, P., Arora, A., Strand, T., Leffler,D., Catassi, C., Green, P., Kelly, C., Ahuja, V., and Makharia, G. (2018). Global prevalence of celiac disease: systematic review and meta-analysis. Clinical Gastroenterology and Hepatology. https://doi.org/16. 10.1016/j.cgh.2017.06.037.

Zorzi, C.Z., Garske, R.P., Flôres, S.H., and Thys, R.C. (2020). Sunflower protein concentrate: a possible and beneficial ingredient for gluten-free bread. Innovative Food Science \& Emerging Technologies, 66.

Open Access. This is an open-access article distributed under the terms of the Creative Commons Attribution 4.0 International License (https://creativecommons.org/licenses/by/4.0/), which permits unrestricted use, distribution, and reproduction in any medium, provided the original author and source are credited, a link to the CC License is provided, and changes - if any - are indicated. (SID_1) 